\title{
Influence of Local Charge Compensation on Site Occupation and Luminescence of Apatites
}

\author{
G. BLASSE \\ Solid State Department, Physical Laboratory, University of Utrecht, Utrecht, The \\ Netherlands
}

Received August 15, 1974; revised September 9, 1974

\begin{abstract}
The apatite structure contains two different sites for the larger cations. It is shown that the principle of local charge compensation can predict the site occupation. This is especially important for an interpretation of the luminescence properties of a number of apatites. The predictions are compared with experimental data. The agreement is satisfactory.
\end{abstract}

\section{Introduction}

Compounds with apatite structure have been used extensively as a host lattice for luminescent ions. The most well-known example is $\mathrm{Sb}^{3+}$ - and $\mathrm{Mn}^{2+}$-coactivated calcium halophosphate which material has found application in fluorescent lamps $(I)$. $\mathrm{The} \mathrm{Sb}^{3+}$ ion shows efficient luminescence in alkaline earth lanthanide apatite silicates too (2). These compounds can also be activated by luminescent lanthanide ions, for example by $\mathrm{Eu}^{3+}$ (3). The apatite lattice has two sites available for cations of this type, viz $(4 f)$ with nine-coordination and $(6 h)$ with seven-coordination. A very clear picture of these coordinations is given in Ref (4). One might expect that the nature of the site will influence the luminescence of the emitting cation. Many studies have, therefore, dealt with the problem which of the two sites is occupied by the emitting cations. We propose here a simple method to predict this site. It is based upon the same idea as Pauling's electrostatic valence rule (5). Our approach differs from that of Felsche (4) who tried to derive cation site occupation in several oxyapatites from the variation of the lattice parameters of the apatite unit cell with the ionic radius of the constituting lanthanides. For the apatites $\mathrm{M}^{+} \mathrm{Ln}_{9}\left(\mathrm{SiO}_{4}\right)_{6} \mathrm{O}_{2}(\mathrm{M}=\mathrm{Li}, \mathrm{Na})$ the $\mathrm{M}^{+}$ion is

supposed to be in (6h), because the $a$ vs $r_{\mathrm{Ln}^{3+}}$ curve shows a kink at a place where the $\mathrm{Na}^{+}$ radius becomes competitive with the lanthanide radius. For lithium, however, there is a kink at the same value of $r_{\mathrm{Ln}^{3+}}$. Also the $\mathrm{Mg}^{2+}$ and $\mathrm{Ca}^{2+}$ ions in $\mathrm{M}_{2}^{2+} \mathrm{Ln}_{8}\left(\mathrm{SiO}_{4}\right)_{6} \mathrm{O}_{2}$ $(\mathrm{M}=\mathrm{Mg}, \mathrm{Ca})$ are placed in $(6 h)$ for the same reasons. Our procedure gives other results which seem to agree with the luminescence data published for these compounds. We will first discuss the oxyapatites (silicates) of the lanthanides and after that the fluoro (chloro)apatites (phosphates).

\section{Oxyapatites of the Lanthanides}

A striking detail of the oxyapatites is the coordination of the $O(4)$ ion. This is the oxygen ion that does not belong to any silicate tetrahedron. It is sometimes called the free oxygen ion. It is coordinated triangularly by three $(6 h)$ cations. Even if these are trivalent lanthanide ions, the sum of the electrostatic bond strength of the cations towards $0(4), \zeta$, is only $9 / 7$, considerably less than 2 as required by Pauling's electrostatic valence principle (4). This results in a very short $\mathrm{Ln}-\mathrm{O}$ distance (5). Further calculation shows that $\zeta$ for the other oxygen ions does not differ significantly from 2 . From this it follows that it must be very 
unfavourable to have cations with large radius and/or low charge in the $(6 h)$ sites in these compounds. Let us see what we can learn from this simple statement.

\section{a. Binary Compounds $\mathrm{Ln}_{9.33} \square{ }_{0.67}\left(\mathrm{SiO}_{4}\right)_{6} \mathrm{O}_{2}$}

It will be clear that we expect that the $(6 h)$ sites are completely filled and that the $(4 f)$ sites contain the lanthanide vacancies. This has also been found from crystallographic investigations (6).

\section{b. Ternary Compounds $\mathrm{M}^{+} \mathrm{Ln}_{9}\left(\mathrm{SiO}_{4}\right)_{6} \mathrm{O}_{2}(\mathrm{M}$ $=L i, N a$ )}

From our considerations we expect the monovalent ions to be in (4f) in contrast with Felsche's proposal (5). This author has also shown that samples $\mathrm{LiLaSiO}_{4}$ studied earlier by us must be $\mathrm{LiLa}_{9}\left(\mathrm{SiO}_{4}\right)_{6} \mathrm{O}_{2}$ in view of the crystallographic data. In Ref. (7) we reported on the $\mathrm{Eu}^{3+}$ luminescence of these compounds. Since $\mathrm{Eu}^{3+}$ is smaller than $\mathrm{La}^{3+}$ we expect the activator ions in $(6 h)$. In view of the low value of $\zeta$ for the surrounding anions the $\mathbf{E u}^{3+}$ charge-transfer band is expected at relatively low energy ( 8 ). This is found indeed, viz $280 \mathrm{~nm}(7)$, a very low value for $\mathrm{Eu}^{3+}$ in silicates. Furthermore, the ${ }^{5} D_{0^{-}}{ }^{7} F_{0}$ emission of $\mathrm{Eu}^{3+}$ in this compound is rather intense indicating a strong linear crystal-field component at the $\mathrm{Eu}^{3+}$ ion (9). It is quite obvious that this is the case in the $(6 h)$ site. The site symmetry is $C_{s}$ with one free oxygen ion in the symmetry plane.

\section{c. Ternary Compounds $\mathrm{M}_{2}^{2+} \mathrm{Ln}_{8}\left(\mathrm{SiO}_{4}\right)_{6} \mathrm{O}_{2}(\mathrm{M}$ is Alkaline Earth)}

Our model predicts the alkaline-earth ions in (4f). Only if the $\mathrm{Ln}^{3+}$ ions are relatively large (e.g., $\mathrm{La}^{3+}$ ) and the $\mathrm{M}^{2+}$ ions small (e.g., $\left.\mathrm{Mg}^{2+}\right)$ it is not excluded that the $\mathbf{M}^{2+}$ ions are also in $(6 h)$. Luminescence of the $\mathrm{Eu}^{3+}$ ion in some of these compounds has been reported by Isaacs (3) and we will try to relate his results with the present discussion.

We expect $\mathrm{Eu}^{3+}$ in the compounds used in the following sites.

$\mathrm{Ca}_{2} \mathrm{La}_{8}\left(\mathrm{SiO}_{4}\right)_{6} \mathrm{O}_{2}$ and $\mathrm{Mg}_{2} \mathrm{La}_{8}\left(\mathrm{SiO}_{4}\right)_{6} \mathrm{O}_{2}$. $\mathrm{Eu}^{3+}$ is expected to enter the (6h) sites because $\mathrm{Eu}^{3+}$ is smaller than $\mathrm{La}^{3+}$. Because the (4f) sites are occupied statistically by equal amounts of alkaline earth and lanthanum ions the crystal field at $\mathrm{Eu}^{3+}$ will vary from site to site. This is confirmed by the luminescent spectra. The $\mathrm{Eu}^{3+}$ emission from the lanthanum compounds resembles that of the lithium compound mentioned above $(3,7)$ : the excitation band peaks at about $285 \mathrm{~nm}$ due to the coordination by a free oxygen ion. Furthermore the ${ }^{5} D_{0}{ }^{7} F_{0}$ emission is stronger than in the corresponding yttrium compounds. The strongest emission line peaks at $626 \mathrm{~nm}$ and the ${ }^{5} D_{0^{-}}{ }^{7} F_{4}$ emission has medium intensity.

$\mathrm{Ca}_{2} \mathrm{Y}_{8}\left(\mathrm{SiO}_{4}\right)_{6} \mathrm{O}_{2}$ and $\mathrm{Mg}_{2} \mathrm{Y}_{8}(\mathrm{SiO})_{6} \mathrm{O}_{2}$. Here $\mathrm{Eu}^{3+}$ is expected to enter the (4f) site because $\mathrm{Eu}^{3+}$ is larger than $\mathrm{Y}^{3+}$. The luminescent properties differ significantly from those of the lanthanum compounds. The excitation band peaks at about $230 \mathrm{~nm}$ (3) indicating a coordination by strongly bound oxygen anions. Since the $(4 f)$ site lacks a pronounced linear crystal field term the ${ }^{5} D_{0}-{ }^{7} F_{0}$ emission is very weak. Furthermore, the ${ }^{5} D_{0}-{ }^{7} F_{4}$ emission is very weak and the strongest emission line peaks at about $611 \mathrm{~nm}$.

$\mathrm{Ca}_{2} \mathrm{Gd}_{8}\left(\mathrm{SiO}_{4}\right)_{6} \mathrm{O}_{2}$. Since $\mathrm{Eu}^{3+}$ is about as large as $\mathrm{Gd}^{3+}$ we expect a statistical distribution of $\mathrm{Eu}^{3+}$ among the $\mathrm{Gd}^{3+}$ sites. These are $(6 h)$ and the half of the $(4 f)$ sites (the other half is occupied by calcium), so that there are three times more $(6 h)$ than $(4 f)$ lanthanides. We expect, therefore, that the luminescence of $\mathrm{Eu}^{3+}$ in the gadolinium compound can be described by a superposition of the spectra of the lanthanum and the yttrium compounds with a dominant contribution by the former. This is in fact the case. The emission spectrum of the Gd compound resembles closely that of the La compound with one marked difference, viz a strong line at $612 \mathrm{~nm}$. This is the dominating line in the $\mathrm{Y}$ compounds. There is a strong excitation band around $265 \mathrm{~nm}$ which is ascribed to $\mathrm{Eu}^{3+}$ in $(6 h)$. We cannot exclude, therefore, a certain preferential excitation of the $\mathrm{Eu}^{3+}$ ions in $(6 h)$. There is another band at about $220 \mathrm{~nm}$ which is also present in the other compounds. This band is not discussed further because it is impossible to derive from the data in Ref. (3) whether this is a host-lattice band or an activator band.

Since the model works well up till here we now turn to other activators in the oxyapatites. 
Wanmaker et al. (2) have reported $\mathrm{Sb}^{3+}$ emission from apatites $\mathrm{M}_{2}^{2+} \mathrm{Ln}_{8}\left(\mathrm{SiO}_{4}\right)_{6} \mathrm{O}_{2}$. The emission consists of a broad band peaking in the region $450-540 \mathrm{~nm}$. Our model predicts the $\mathrm{Sb}^{3+}$ ion (which is smaller than the lanthanides) in ( $6 h)$. This cannot be verified from the luminescent data, the bands being broad and their structural dependence unknown. It is striking that the position of the maximum of the $\mathrm{Sb}^{34}$ emission depends markedly on the choice of $\mathrm{Ln}^{3+}$ and practically not on that of $\mathrm{M}^{2+}(2)$. For $\mathrm{Sb}^{3+}$ in (4f) this would not be expected, the $(4 f)$ sites forming linear chains parallel to the hexagonal $c$ axis. For $\mathrm{Sb}^{3+}$ in (6h) this dependence is more conceivable, since then the $\mathrm{Sb}^{3+}$ coordinates the free oxygen ion together with two other $(6 h)$ site ions, i.e., $\mathrm{Ln}^{3+}$ ions. Let us now turn to the calcium halophosphates.

\section{Calcium Halophosphates $\mathrm{Ca}_{10}\left(\mathrm{PO}_{4}\right)_{6} \mathrm{X}_{2}$.}

In $\mathrm{Ca}_{10}\left(\mathrm{PO}_{4}\right)_{6} \mathrm{~F}_{2} \zeta$ for the $\mathrm{F}^{-}$ion is found to be $6 / 7$, whereas $\zeta$ for the $\mathrm{O}^{2-}$ ions is very near to 2 . This means that we have in principle the same situation as in the oxyapatites discussed above, but that the lack of charge compensation is less pronounced. We expect, therefore, that trivalent cations in fluorophosphate will mainly occupy the $(6 h)$ sites. The luminescence data confirm this expectation as will be shown now.

Luminescence from $\mathrm{Eu}^{3+}$ in fluoroapatite has been reported by Chafaï et al. (10). From the fact that the relative peak intensities in the emission spectrum are constant for different $\mathrm{Eu}^{3+}$ concentrations they conclude that $\mathrm{Eu}^{3+}$ occupies only one of the sites. The authors conclude that this must be the $(4 f)$ site. This conclusion is based upon the fact that they observe the ${ }^{5} D_{0}-{ }^{7} F_{0}$ emission which should be allowed for $\mathrm{Eu}^{3+}$ in (4f), and forbidden for $\mathrm{Eu}^{3+}$ in (6h). This is obviously incorrect (see Table I). As argued above this emission is allowed for both sites, but should be even stronger for the $(6 h)$ site. They further observe that the ${ }^{5} D_{0^{--}} F_{4}$ emission is weak and that the ${ }^{5} D_{0}-{ }^{7} F_{2}$ emission dominates strongly. The latter fact is not expected for a fluorophosphate (11). We are, therefore, inclined to believe that the $\mathrm{Eu}^{3+}$ ion occupies a $(6 h)$ site, as expected
TABLE I

NUMBER OF LINES EXPECTED FOR ${ }^{5} D_{0}-{ }^{7} F_{n}(n=0,1,2)$ Transitions for $\mathrm{Eu}^{3+}$ under $C_{3}$ AND $C_{s}$ SyMmetry

\begin{tabular}{cccc}
\hline Site symmetry & ${ }^{5} D_{0}-{ }^{7} F_{0}$ & ${ }^{5} D_{0^{-}}{ }^{7} F_{1}$ & ${ }^{5} D_{0}{ }^{7} F_{2}$ \\
\hline$C_{3}$ & 1 & 2 & 3 \\
$C_{s}$ & 1 & 3 & 5 \\
\hline
\end{tabular}

from our model, and that it is charge-compensated by an oxygen ion on the fluorine site. This explains the presence of the ${ }^{5} D_{0}-{ }^{7} D_{0}$ emission and the intensity of the ${ }^{5} D_{0}-{ }^{7} F_{2}$ emission.

The $\mathrm{Sb}^{3+}$ ion is also expected on the $(6 h)$ sites. From the work of Soules et al. (12) it is clear that $\mathrm{Sb}^{3+}$ is not in (4f) sites, neither in compensated nor in uncompensated fluorophosphate.

For $\mathrm{Mn}^{2+}$ in fluorophosphate the charge compensation principle predicts a slight preference for $(6 h)$ sites, because the $\mathrm{Mn}^{2+}$ ion is somewhat smaller than the $\mathrm{Ca}^{2+}$ ion. Optical and EPR measurements $(13,14)$ are, however, not very conclusive. Reference (14) reports $\mathrm{Mn}^{2+}$ in (4f) only, Ref. (13) reports also large amounts of $\mathrm{Mn}$ in (6h) associated with an oxygen vacancy.

The chloroapatite $\left.\mathrm{Ca}_{10}(\mathrm{PO})_{4}\right)_{6} \mathrm{Cl}_{2}$ has a slightly different monoclinic crystal structure, where each $\mathrm{Cl}^{-}$ion is surrounded by six $\mathrm{Ca}^{2+}$ ions so that $\zeta$ for $\mathrm{Cl}^{-}$is 1.5 which is much too high. The value of $\zeta$ for oxygen is slightly less than 2. We therefore expect $\mathrm{Sb}^{3+}$ on $(4 f)$ sites unless it is charge-compensated by $\mathrm{O}^{2-}$ on chlorine sites. The behaviour of $\mathrm{Sb}^{3+}$ in chloro- (and also fluoro-) apatite has been studied thoroughly by Davis et al. (15). We are especially interested in their results on samples without oxygen compensation. They find an emission at about $400 \mathrm{~nm}$ for these samples. This is at much shorter wavelengths than the emission of oxygen-compensated samples which emit at about $490 \mathrm{~nm}$. The authors hesitate to assign the $400 \mathrm{~nm}$ emission to $\mathrm{Sb}^{3+}$ in one of the two sites. It seems to us that it is not likely that the $400 \mathrm{~nm}$ emission in the fluoro- and chloroapatite is due to $\mathrm{Sb}^{3+}$ in $(6 h)$, because the nature of the neighbouring halogen ion will influence the spec- 
tral position of the electronic transitions as is well known (16). We are, therefore, left with the conclusion that $\mathrm{Sb}^{3+}$ in the chloroapatites is in (4f), if it is not oxygen-compensated. We realize that the experimental evidence for this conclusion is not very strong, so that the agreement with our expectation is not very convincing.

For $\mathrm{Mn}^{2+}$ we expect a weak preference for (4f). Experimental data (14) indicate a statistical distribution of manganese among the calcium sites, so that we conclude that the change in manganese distribution going from fluoro- to chloroapatite is predicted correctly. The difference between $\mathrm{Mn}^{2+}$ and $\mathrm{Ca}^{2+}$ is so small that this is the best result to be expected.

We conclude that an extremely simple model can predict site occupations correctly in the apatite structure. A more general applicability will be investigated.

\section{References}

1. See, e.g., J. L. Ouweltues, "Luminescence and Phosphors, in Modern Materials," Vol. 5, p. 161, Academic Press, New York, 1965.

2. W. L. Wanmaker, J. W. Ter VRugt, and J. G. VerliJSDONK, J. Solid State Chem. 3, 452 (1971).
3. T. J. IsAacs, J. Electrochem. Soc. 120, 654 (1973). 4. L. Pauling, "The Nature of the Chemical Bond", 2nd ed. chapter 48b. Oxford University Press, London.

5. J. FELSCHE, Structure and Bonding 13, 99 (1973); J. Solid State Chem. 5, 266 (1972).

6. Yu. I. Smolin and Yu. F. Shepelev, Izv. Akad. Nauk SSSR, Inorg. Mater. 5, 1823 (1969).

7. G. Blasse AND A. Bril, J. Inorg. Nucl. Chem. 29, 2231 (1967).

8. G. Blasse, J. Chem. Phys. 45, 2356 (1966); G. Blasse and A. Bril, Z. Physik. Chemie N.F. 57, 187 (1968,

9. W. C. NieuWport AND G. Blasse, Solid State Comm. 4, 227 (1966).

10. M. Chafaï, J. C. Heughebaert, C. Linarès, F. Gaume-Mahn, and G. Montel, C.R. Acad. Sci. Paris Série C 272, 1804 (1971).

11. G. Blasse ANd A. Bril, J. Chem. Phys. 50, 2974 (1969).

12. T. F. Soules, T. S Davis, ANd E R KREIDler, J. Chem. Phys. 55, 1056 (1971).

13. F. M. Ryan, R. C. Ohlmann, J. Murphy, R. MAZELSKY, G. R. WAGNER, AND R. W. WARREN, Phys. Rev. B2, 2341 (1970).

14. W. W. PIPER, J. Luminescence 1-2, 669 (1970).

15. T. S. Davis, E. R. Kreidler, J. A. Parodi, AND T. F. SoulEs, J. Luminescence 4, 48 (1971).

16. C. K. JøRGENSEN, "Absorption Spectra and Chemical Bonding in Complexes", chapter 10, Pergamon Press, New York. 